\title{
Carbohydrate Constituents of the Marine Algae of Sri Lanka Part II. Composition and Sequence of Uronate Residues in Alginates from some Brown Seaweeds
}

\author{
S. Shyamali M. De Silva and N. Savitri Kumar \\ Department of Chemistry, University of Peradeniya, Peradeniya, Sri Lanka
}

(Date of receipt: 22 March 1983)

(Date of acceptance: 14 August 1984)

\begin{abstract}
The ratio of mannuronic acid residues to guluronic acid residues ( $M / G$ ratio) of sodium alginate extracted from Cystoseira trinodis, Turbinaria conoides and Sargassum $\mathrm{sp}$. was determined using high resolution $1 \mathrm{H}-\mathrm{NMR}$ spectroscopy. The intensities of the signals due to $\mathrm{H}-5$ of guluronate residues and $\mathrm{H}-1$ of both guluronate and mannuronate residues were used. The alginate samples were found to be rich in guluronate residues, and the polymer chains are likely to be composed of long blocks of guluronate residues, short blocks of mannuronate residues and a small proportion of blocks containing both uronide residues.
\end{abstract}

\section{Introduction}

Alginic acid is a mucilaginous polysaccharide which has been found in all species of brown seaweeds examined, but is not present in any other plant tissue. ${ }^{9}$ The polysaccharide is a linear glycuronan which consists of $(1 \rightarrow 4)$-linked residues of $D$-mannuronic acid and $L$ - guluronic acid arranged in a block fashion in the polymer chain. Blocks containing one type of residue (MM blocks and GG blocks) are separated by segments in which the two residues alternate (Figure 1).5,6,7 Physical properties of alginates depend on its uronic acid composition, i.e. the ratio of mannuronic acid residues to guluronic acid residues ( $M / G$ ratio), and also upon the relative proportion of the tnree types of blocks (MM, GG and MG). Both the $M / G$ ratio and the monomer sequence distribution changes from one species of brown alga to another.

Penman and Sanderson ${ }^{8}$ found that ${ }^{1} \mathrm{H}-\mathrm{NMR}$ spectroscopy could be used to distinguish between signals due to $\mathrm{H}-1$ and $\mathrm{H}-5$ in the guluronic acid residues and $\mathrm{H}-1$ from mannuronic acid residues in homopolymeric blocks obtained by partial hydrolysis of alginates. Grasdalen et $a l^{2}$ using high resolution ${ }^{1} \mathrm{H}-\mathrm{NMR}$ spectroscopy were able to distinguish between $\mathrm{H}-5$ of guluronic acid residues with a mannuronic acid neighbour (GM sequence) from those with a guluronic acid neighbour (GG sequence). In this paper we describe the results obtained using this method, in analysing alginate samples isolated from four species of brown seaweeds collected from the coastal regions of Sri Lanka. 


\section{Results and Discussion}

The 1H-NMR spectra of the partially depolymerised alginate samples were interpreted using the method described by Grasdalen et al.2 The intensities of (i) the doublet centred at $5.1 \mathrm{ppm}$ due to the $\mathrm{H}-1$ of the G-residues $\left(\mathrm{I}_{A}\right)$ (see Figure 2), (ii) the singlet at $4.7 \mathrm{ppm}$ due to $\mathrm{H}-1$ of the M-residues and $\mathrm{H}-5$ of GM residues. ( $\left.I_{B}\right)$ and (iii) the singlet at $4.5 \mathrm{ppm}$ due to $H-5$ of $G G$ residues $\left(I_{C}\right)$ were measured. The $M / G$ ratios as well as the doublet frequencies were calculated and are given in Table 1 for the alginates from the four species of brown algae examined by us.

The $1 \mathrm{H}-\mathrm{NMR}$ spectra of the samples from Turbinaria conoides and Sargassum sp. (oval), were re-run and amplified. In these two samples the intensities of the signals $\mathrm{A}, \mathrm{B}$ and $\mathrm{C}$ were also obtained by planimetry. These values were found to be different and are considered to be more accurate than those obtained by integration. They were also found to agree with preliminary results obtained from ${ }^{13} \mathrm{C}-\mathrm{NMR}$ spectroscopy ${ }^{3}, 4$ where intensities of the signals were calculated by planimetry (see Table 1 ).

TABLE 1. Composition of Alginates

\begin{tabular}{|c|c|c|c|c|c|c|c|c|}
\hline \multirow[t]{2}{*}{ Seaweed } & & \multicolumn{2}{|c|}{ Composition } & \multirow[b]{2}{*}{$F_{M M}$} & \multicolumn{3}{|c|}{ Doublet frequency } & \multirow[t]{2}{*}{$M / G$ ratic } \\
\hline & & $F_{M}$ & $F_{G}$ & & $F_{M G}$ & $F_{G M}$ & $F_{G G}$ & \\
\hline \multicolumn{2}{|l|}{ 1. Cystoseira } & 0.19 & 0.81 & 0.05 & 0.14 & 0.14 & 0.67 & 0.23 \\
\hline $\begin{array}{l}\text { 2. Turbinaria } \\
\text { conoides }\end{array}$ & a & 0.35 & $\begin{array}{l}0.65 \\
0.76\end{array}$ & 0.28 & 0.07 & 0.07 & 0.58 & 0.54 \\
\hline 3. Sargassum & $\begin{array}{l}\text { b } \\
\text { c }\end{array}$ & $\begin{array}{l}0.24 \\
0.25\end{array}$ & $\begin{array}{l}0.76 \\
0.75\end{array}$ & $\begin{array}{l}0.13 \\
0.19\end{array}$ & $\begin{array}{l}0.11 \\
0.06\end{array}$ & $\begin{array}{l}0.11 \\
0.06\end{array}$ & $\begin{array}{l}0.64 \\
0.69\end{array}$ & $\begin{array}{l}0.32 \\
0.33\end{array}$ \\
\hline $\begin{array}{l}\text { sp. (linear) } \\
\text { 4. Sargassum }\end{array}$ & $\mathbf{a}$ & 0.35 & 0.65 & 0.29 & 0.06 & 0.06 & 0.59 & 0.54 \\
\hline sp. (oval) & $\mathbf{a}$ & 0.26 & 0.74 & 0.20 & 0.06 & 0.06 & 0.68 & 0.35 \\
\hline & $\mathbf{b}$ & 0.33 & 0.67 & 0.25 & 0.08 & 0.08 & 0.59 & 0.49 \\
\hline & c & 0.34 & 0.66 & 0.27 & 0.07 & 0.07 & 0.59 & 0.52 \\
\hline
\end{tabular}

\footnotetext{
a ${ }^{1} \mathrm{H}-\mathrm{NMR}$, int. by integration

b ${ }^{1} \mathrm{H}-\mathrm{NMR}$, int. by planimetry

c ${ }^{13} \mathrm{C}$-NMR, int. by planimetry
}

The results indicate that all four alginate samples are rich in guluronic acid residues, and the doublet frequencies give an idea of the block character of each alginate. Therefore these four samples of sodium alginate probably contain long blocks of $G$, shorter blocks of $M$ and very little alternate MG and GM blocks. 


\section{Methods/Experimental}

Sodium alginate was isolated from four species of brown seaweeds Cystoseira trinodis, Turbinaria conoides and two unidentified species of Sargassum referred to as Sargassum sp. (linear) and Sargassum sp. (oval) with respect to the shape of their fronds. These seaweeds were washed, sundried and milled. Samples of seaweed $(50 \mathrm{~g})$ were extracted successively as follows (i) twice with $2 \% \mathrm{CaCl}_{2}$ solution $(300 \mathrm{ml})$ at room temperature for $4 \mathrm{~h}$; (ii) twice with $2 \% \mathrm{CaCl}_{2}$ solution $(300 \mathrm{ml})$ at $70^{\circ} \mathrm{C}$ for $4 \mathrm{~h}$; (iii) four times with dil. $\mathrm{HCl}(300 \mathrm{ml}, \mathrm{pH} 2)$ at $70^{\circ} \mathrm{C}$ for $4 \mathrm{~h}$; (iv) five times with $3 \% \mathrm{Na}_{2} \mathrm{CO}_{3}$ solution $(300 \mathrm{ml})$ at $50^{\circ} \mathrm{C}$ for $4 \mathrm{~h}$. The combined $\mathrm{Na}_{2} \mathrm{CO}_{3}$ extract was poured with stirring into ethanol $(61)$. The precipitate was filtered, dried, dissolved in water and stirred with $2 \% \mathrm{CaCl}_{2}$ solution until precipitation was complete. The calcium alginate was suspended in $0.5 \mathrm{M} \mathrm{HCl}$, stirred occasionally for $3 \mathrm{~h}$ and filtered. The filtrate was tested for $\mathrm{Ca}^{++}$ions. The residue was washed with $0.5 \mathrm{M} \mathrm{HCl}$ until the filtrate was free of $\mathrm{Ca}^{++}$ions. The alginic acid was suspended in water and titrated with $0.1 \mathrm{M} \mathrm{NaOH}$ until the $\mathrm{pH}$ reached 7 , when all the alginic acid was dissolved. The solution was dialysed for two days and then freeze dried to give a white powder. The $M / G$ ratio and monomer sequence distribution of each sample were determined by PMR spectroscopy $\left(t \sim 6\right.$ secs). The spectra were recorded at $90^{\circ} \mathrm{C}$ in order to increase the spectral resolution and to shift the solvent peak upfield away from the low field spectral region. ${ }^{1} \mathrm{H}$-Chemical shifts were expressed in ppm downfield from the internal standard sodium 3-(trimethylsilyl) propane sulphonate. The area under each peak in the low field region was found by integration, and in two cases by planimetry.

\subsection{Calculation}

The $M / G$ ratios and the doublet frequencies were calculated as follows. Quantitatively the mole fraction of $\mathrm{G}\left(\mathrm{F}_{\mathrm{G}}\right)$ and the doublet frequency $\left(\mathrm{F}_{\mathrm{GG}}\right)$ are related to the intensities (I) of the respective lines by the following relationships.

$$
F_{G}=\frac{I}{I_{B}+I_{C}}, \quad F_{G G}=\frac{I}{I_{B}+\frac{I}{C}}
$$

The mole fraction of $M$ is derived from the normalization condition

$$
\mathrm{F}_{\mathbf{G}}+\mathrm{F}_{\mathbf{M}}=1
$$






FJgURE 1 - Structure of Alginic Acid showing the block character of the Uronic Acid Residues. 


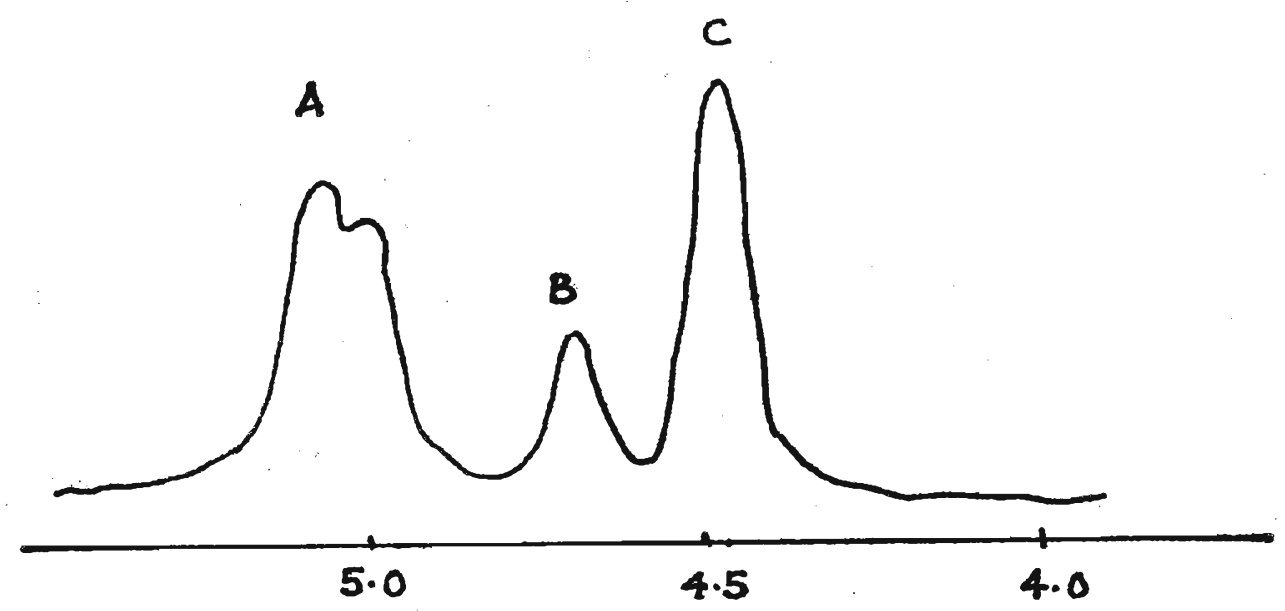

Chemical Shift (p.p.m.)

FIGURe 2 - The Low Field Region of the $99.6 \mathrm{MHz}$ FT - ${ }^{1}$ H-N.m.r. Spectrum of a Partially Depolymerized Alginate Rich in Guluronic Acid Residues.

$\mathrm{A}=\mathrm{H}-1$ of $\mathrm{G}$ Residues

$\mathrm{B}=\mathrm{H}-1$ of $\mathrm{M}$ Residues $+\mathrm{H}-5$ of $\mathrm{GM}$ Residues

$\mathrm{C}=\mathrm{H}-5$ of $\mathrm{GG}$ Residues 
The relationship between the doublet frequencies and the mole fractions are given by

$$
F_{G G}+F_{G M}=F_{G} \text { and } F_{M M}+F_{M G}=F_{M}
$$

For long chains where the average degree of polymerization, $\overline{\mathrm{dp}} \mathrm{p}_{\mathrm{n}}>20$, corrections for the reducing end residues may be neglected so that,

$$
\mathrm{F}_{\mathrm{MG}}=\mathrm{F}_{\mathrm{GM}}
$$

\section{Acknowledgements}

We thank Prof. S. Balasubramaniam (University of Peradeniya) for collection and identification of seaweeds, Drs. Per Åman (Swedish University of Agricultural Sciences) and Hans Grasdalen (University of Trondheim) for their help and interest. We gratefully acknowledge the use of facilities at the Dept. of Chemistry, Swedish University of Agricultural Sciences. We also thank the International Foundation for Science, the Natural Resources, Energy and Science Authority of Sri Lanka and the International Seminar in Chemistry, Uppsala for financial assistance.

\section{References}

1. Dantanarayana, A. P., Kumar, N. S., Sultanbawa, M. U. S. \& Balasubramaniam, S. (1981). J. Natn. Sci. Coun. Sri Lanka, 9 (1), 9.

2. Grasdalen, H., larsen, B. \& Smidsrö̀, O. (1979). Carbohydr. Res., 68:23-31.

3. Grasdalen, H., Larsen, B. \& Smidsrö, O. (1979). Proc. Int. seaweed symp. Princeton Science Press, Princeton, p. 309-317.

4. Grasdalen, H., Larsen, B. \& Smidsrod, O. (1981). Carbohydr. Res. 89:179-191.

5. Haug, A., Larsen, B. \& Smidsrö, O. (1966). Acta. Chem. Scand. 20:183-190.

6. Haug, A., Larsen, B. \& Smidsrö̈, O. (1974). Carbohydr. Res. 32:217-225.

7. Larsen, B., Smidsoö, O., Painter, T. \& Haug, A. (1970). Acta Chem. Scand., 24:726-728.

8. Penman, A. \& Sanderson, G. R. (1972). Carbohydr. Res., 25:273-282.

9. Pfractival, E. \& McDowell, R. H. (1981). Plant carbohydrates II Encyclopaedia of Plant physiology New Series, Vol. 13B edited by W. Tanner and F. A. Loewus. 